\title{
O PROGRAMA MUNICÍPIO VERDEAZUL E A ARBORIZAÇÃO URBANA
}

Eliana Cristina Generoso Konrad ${ }^{1}$; Silvia Maria de Almeida Lima Costa ${ }^{2}$;Regina Maria Monteiro de Castilho ${ }^{3}$

\section{RESUMO}

O Programa Município Verde Azul (PMVA) criado pela Secretaria do Meio Ambiente do Estado de São Paulo(SMA) visa descentralizar a política ambiental no estado e conta com a participação da sociedade neste modelo de gestão ambiental. A Diretiva Ambiental Arborização Urbana (DAAU) compõe um conjunto de diretrizes relevantes à gestão ambiental municipal definida pela SMA para o PMVA. Este trabalho teve por objetivo identificar, caracterizar e analisar os dez primeiros municípios certificados em 2008, 2009, 2010, 2011 e 2012.Identificaram-se os seguintes municípios precedidos de suas Regiões Administrativas: Araçatuba (Buritama, Gabriel Monteiro, Guaraçaí, Guararapes, Pereira Barreto e Piacatu); Barretos (Barretos e Viradouro); Bauru (Cabrália Paulista e Lins); Central (Araraquara); Presidente Prudente (Anhumas, Martinópolis e Teodoro Sampaio); Ribeirão Preto (Altinópolis, Luiz Antônio e Santa Rosa de Viterbo); São José do Rio Preto (Aspásia, Fernandópolis, Jales, Mira Estrela, Novo Horizonte, Orindiúva, Paulo de Faria, Pontalinda, Potirendaba e Santa Fé do Sul) e Sorocaba (Angatuba, Botucatu, Itu, Piraju, Quadra, São Manuel, Sarutaiá, Sorocaba e Taquarituba). O município de Santa Fé do Sul certificou-se em 2008, 2009, 2011 e 2012. O maior índice de projeção de copa foi observado no município de Martinópolis, com 59 m²/hab, quarto colocado no ranking de 2010.

Palavras-chave: Gestão Ambiental; Política Pública;Selo Ambiental.

\section{THE PROGRAM BLUE GREEN MUNICIPAL AND URBAN AFFORESTATION}

\section{ABSTRACT}

The program Municipal Green Blue (PMVA) created by the Department of Environment of the State of São Paulo (SMA) aims to decentralize environmental policy in the state and with the participation of society in this model of environmental management. The Urban Forestry Environmental Policy (DAAU) comprises a set of guidelines relevant to municipal environmental management defined by the SMA for PMVA. This study aimed to identify, characterize and analyze the top ten counties certified in 2008, 2009, 2010, 2011 and 2012. Identifiedthefollowingcountiespreceded its AdministrativeRegions: Araçatuba (Buritama, Gabriel Monteiro, Guaraçaí, Guararapes, Pereira Barreto andPiacatu); Barretos (Barretos and Viradouro); Bauru (Cabrália Paulis ${ }^{5}$ ta and Lins); Central (Araraquara); Presidente Prudente (Anhumas, Martinópolis and Teodoro Sampaio), Ribeirão Preto (Altinópolis, Luiz Antonioand Santa Rosa de Viterbo), São José do Rio Preto (Aspásia, Fernandópolis, Jales, Mira Estrela, Novo Horizonte, Orindiúva, Paulo de Faria, Pontalinda , Potirendaba and Santa Fé do Sul) and Sorocaba (Angatuba, Botucatu, Itu, Piraju, Quadra, São Manuel, Sarutaiá, Sorocaba and Taquarituba). The town of Santa FédoSul certified in 2008, 2009, 2011 and 2012. The largest index tree projection was observed in the town of Martinópolis, with $59 \mathrm{~m}^{2} /$ hab, placed fourth in the 2010 ranking.

Key-words: Environmental Management; Public Policy; Environmental Seal.

\footnotetext{
${ }^{1}$ Engenheira Agrônoma, doutoranda em Sistema de Produção, UNESP, Faculdade de engenharia de Ilha Solteira, Ilha Solteira, SP. eliana_generoso@bol.com.br;

${ }^{2}$ Docente do Departamento de Fitotecnia, Tecnologia de Alimentos e Sócio Economia,UNESP, Faculdade de Engenharia de Ilha Solteira. smslc@agr.feis.unesp.br.

${ }^{3}$ Docente do Departamento de Fitotecnia, Tecnologia de Alimentos e Sócio Economia, UNESP, Facuoldade de Engenharia de Ilha Solteira. castilho_re@hotmail.com

${ }^{4}$ recebido em 29.10.2013 e aceito para publicação em 15.12.2013
} 
A migração da população para os centros urbanos e a falta de planejamento do desenho das cidades, tem sido uma das principais causas da baixa qualidade de vida nestes espaços. Este processo de ocupação tem gerado grandes desafios, no que se refere às estratégias do poder público na definição das políticas para fomentar modelos de gestão.

O Programa Município Verde Azul (PMVA), foi criado em 2007, sob a denominação de Projeto Município Verde assumindo posteriormente, a denominação de Projeto Município VerdeAzul no exercício de 2009 da Secretaria de Meio Ambiente do Estado de São Paulo, quando passa a considerar os recursos hídricos. Este programa foi criado com o objetivo de descentralizar a política ambiental, com base na eficiência da gestão ambiental valorizando a base da sociedade(AMBIENTE, 2013).

A adesão voluntária do município ao novo formato da política ambiental pode resultar em um certificado ou rótulo ambiental. De acordo com a associação Brasileira de Normas Técnicas (ABNT, 2013), a rotulagem ambiental é uma metodologia voluntária de certificação e rotulagem de desempenho ambiental de produtos ou serviços. No caso do PMVA a conquista do certificado caracteriza municípios ambientalmente corretos dando prioridade no acesso aos recursos públicos (AMBIENTE, 2013)

Segundo proposta da SMA,a política ambiental incluída no PMVAtem por objetivo gerenciar a arborização urbana e a manutenção de áreas verdes municipais selecionando espécies a serem utilizadas, preferencialmente as nativas da região, incluindo-se, manutenção do viveiro municipal para suprimento de mudas tanto para a arborização urbana, quanto para recuperação de mata ciliar, tendo por base em uma legislação municipal que regulamente as atividades desta gestão(AMBIENTE, 2013).

A arborização desempenha funções importantes, pois produz sombra, reduz a luminosidade excessiva, diminui a intensidade dos ruídos, melhora a qualidade do ar e as condições de solo, favorece a infiltração da água das chuvas, além de influenciar o aspecto paisagístico do ambiente e a biodiversidade (Demattê, 2001). Paiva (2001) considera que a arborização pode afetar positivamente o efeito visual de um ambiente.

Considerando que a arborização melhora as condições de vida nas cidades, este trabalho teve por objetivos identificar os municípios que atingiram asdezprimeiras colocações no ranking estadual, nos anos de 2008, 2009, 2010, 2011 e 2012, os critérios atendidosparaa gestão da arborização municipal propostas pelo projeto Município Verde Azul, em relação à diretiva Arborização Urbana e a caracterização destes municípios em relação a dados populacionais, região administrativa, PIB per capta e grau de urbanização.

\section{MATERIAIS E MÉTODOS}

O selo Projeto Município Verde foi lançado em 2007 e instituído em 2008 pela Resolução SMA009 de 31 de Janeiro de 2008. Com a Resolução
SMA-055 de 11 agosto de 2009divulgou-se a alteração da denominação Projeto Ambiental Estratégico Município Verde para Projeto Eliana Cristina Generoso Konrad et al 
Ambiental Estratégico Município VerdeAzul, no sentido de enfatizar a gestão compartilhada das águas. Em 2011 aconteceu a conversão do Projeto em Programa Município VerdeAzul (PMVA). Este programa possui em sua estrutura, 10 diretivas, compostas por critérios, que desencadeadas pela administração pública municipal influenciam a obtenção da certificação ambiental, Município VerdeAzul (AMBIENTE, 2013).

Para análise deste modelo de política pública ambiental procurou-se levantar as informações sobre a diretiva Arborização Urbana (AU) e sobre os municípios, como,critérios estabelecidos para serem atendidos pelos municípios, ranking de classificação (AMBIENTE, 2013); região administrativa, população (hab), área geográfica $\left(\mathrm{km}^{2}\right)$, densidade demográfica $\left(\mathrm{hab} / \mathrm{m}^{2}\right)$, segundo IBGE (2013); grau de urbanização (\%) e PIB (Produto Interno Bruto) per capta, em reais correntes (FUNDAÇÃO SEADE), órgão vinculado à Secretaria de Planejamento e Desenvolvimento Regional do Estado de São Paulo (SEADE, 2013). Para o levantamento tanto dos critérios como da colocação geral no ranking foram considerados os anos de 2008, 2009, 2010, 2011 e 2012, que será tratado na seqüência por período 2008-2012. Em relação aos critérios descreveu-se a estrutura considerada no Indicador de Atendimento (ID) da diretiva (AU) e do Indicador de ação Pró-ativa do município (PRO).

\section{RESULTADOS E DISCUSSÃO}

$\mathrm{Na}$ Tabela 1 encontram-se as informações que caracterizamos 37 municípios identificados ocupando as 10 primeiras colocações noPMVA, no período 2008-2012.

O Estado de São Paulo é dividido em 14 Regiões Administrativas (RA- Central, Araçatuba, Barretos, Bauru, Campinas, Franca, Marília, Presidente Prudente, Registro, Ribeirão Preto, Santos, São José do Rio Preto, São José dos Campos e Sorocaba),destas oito possuem municípios certificados pelo PMVA(Tabela 1) e quatro Regiões Metropolitanas (RM), a da Baixada Santista, de São Paulo, a de Campinas e a do Vale do Paraíba e Litoral Norte (Planejamento, 2013). Tanto a RA de São José do Rio Preto quanto a RA de Sorocaba, destacaram-se entre as demais identificadas, pelo número de municípios premiados pelo PMVA (2008-2012), ou seja, 10 em cada uma das regionais.

Segundo informações baseadas na Relação Anual de Dados Sociais (RAIS) de 2008, a RA de São José do Rio Preto localizada no Noroeste do estado é formada por 96 municípios e faz divisa com os Estados de Mato Grosso do Sul e Minas Gerais. A rodovia Washington Luís é a principal via de acesso. Já a RA de Sorocaba é servida pelas rodovias Presidente Castello Branco e Raposo Tavares e é formada por 79 municípios (PLANEJAMENTO, 2010). 
Tabela 1.Caracterização, Região Administrativa, grau de urbanização e PIB dos 10 primeiros municípios certificados pelo PMVA no período 2008-2012.

\begin{tabular}{|c|c|c|c|c|c|c|c|}
\hline \multicolumn{2}{|c|}{ MUNICÍPIO } & \multirow{2}{*}{$\begin{array}{c}\text { POPULAÇÃO } \\
* \\
15.607\end{array}$} & \multirow{2}{*}{$\begin{array}{l}\begin{array}{c}\text { ÁREA } \\
(\mathbf{k m} 2)^{*}\end{array} \\
929,836 \\
\end{array}$} & \multirow{2}{*}{$\begin{array}{c}\text { DD } \\
\text { (hab/m2) }\end{array}$} & \multirow{2}{*}{$\begin{array}{l}\text { REGIÃO** } \\
\text { Ribeirão Preto }\end{array}$} & \multirow{2}{*}{$\begin{array}{c}\begin{array}{c}\text { GU } \\
(\%)\end{array} \\
87,37\end{array}$} & \multirow{2}{*}{$\begin{array}{c}\begin{array}{c}\text { PIB } \\
\text { R\$** }\end{array} \\
14.877,19\end{array}$} \\
\hline 1 & Altinópolis & & & & & & \\
\hline 2 & Angatuba & 22.210 & 1027,99 & 21,61 & Sorocaba & 71,83 & $15.957,25$ \\
\hline 3 & Anhumas & 3.738 & 320,42 & 11,67 & Presidente Prudente & 81,85 & $9.390,66$ \\
\hline 4 & Araraquara & 208.662 & 1004,00 & 207,83 & Central & 97,16 & $23.504,98$ \\
\hline 5 & Aspásia & 1.809 & 69,34 & 26,09 & São José do Rio Preto & 69,49 & $10.155,43$ \\
\hline 6 & Barretos & 112.101 & 1565,64 & 71,60 & Barretos & 96,95 & $14.556,77$ \\
\hline 7 & Botucatu & 127.328 & 1483,00 & 85,86 & Sorocaba & 96,35 & $22.496,65$ \\
\hline 8 & Buritama & 15.418 & 326,76 & 47,19 & Araçatuba & 94,22 & $14.747,81$ \\
\hline 9 & Cabrália Paulista & 4.365 & 239,91 & 18,19 & Bauru & 86,54 & $25.967,22$ \\
\hline 10 & Coronel Macedo & 5.001 & 303,93 & 16,45 & Sorocaba & 77,29 & $10.971,63$ \\
\hline 11 & Fernandópolis & 69.696 & 550,03 & 117,62 & São José do Rio Preto & 96,94 & $15.392,22$ \\
\hline 12 & Gabriel Monteiro & 2.708 & 138,55 & 19,55 & Araçatuba & 83,35 & $25.608,50$ \\
\hline 13 & Guaraçaí & 8.435 & 569,87 & 14,80 & Araçatuba & 78,88 & $11.152,58$ \\
\hline 14 & Guararapes & 30.597 & 956,35 & 31,99 & Araçatuba & 92,55 & $17.949,97$ \\
\hline 15 & Itu & 154.147 & 640,00 & 240,85 & Sorocaba & 93,59 & $27.250,78$ \\
\hline 16 & Jales & 47.012 & 368,52 & 127,57 & São José do Rio Preto & 94,10 & $13.370,17$ \\
\hline 17 & Lins & 71.432 & 570,24 & 125,27 & Bauru & 98,83 & $26.195,80$ \\
\hline 18 & Luiz Antônio & 11.286 & 598,44 & 18,86 & Ribeirão Preto & 96,58 & $51.439,62$ \\
\hline 19 & Martinópolis & 24.219 & 1252,72 & 19,33 & Presidente Prudente & 83,99 & $11.466,86$ \\
\hline 20 & Mira Estrela & 2.820 & 216,83 & 13,01 & São José do Rio Preto & 66,71 & $12.384,99$ \\
\hline 21 & Novo Horizonte & 36.593 & 931,67 & 39,28 & São José do Rio Preto & 93,05 & $21.540,83$ \\
\hline 22 & Orindiúva & 5.675 & 248,11 & 22,87 & São José do Rio Preto & 92,03 & $17.539,74$ \\
\hline 23 & Paulo de Faria & 8.589 & 738,29 & 11,63 & São José do Rio Preto & 90,23 & $12.826,93$ \\
\hline 24 & Pereira Barreto & 24.962 & 978,89 & 25,50 & Araçatuba & 93,08 & $27.611,89$ \\
\hline 25 & Piacatu & 5.287 & 232,36 & 22,75 & Araçatuba & 88,20 & $10.277,27$ \\
\hline 26 & Piraju & 28.475 & 504,51 & 56,44 & Sorocaba & 89,92 & $11.819,82$ \\
\hline 27 & Pontalinda & 4.074 & 210,19 & 19,38 & São José do Rio Preto & 82,99 & $9.119,59$ \\
\hline 28 & Potirendaba & 15.449 & 342,00 & 45,17 & São José do Rio Preto & 89,87 & $18.261,47$ \\
\hline 29 & Quadra & 3.236 & 205,66 & 15,73 & Sorocaba & 25,60 & $19.001,78$ \\
\hline 30 & Santa Fé do Sul & 29.239 & 208,22 & 140,43 & São José do Rio Preto & 96,06 & $19.174,26$ \\
\hline 31 & Santa R.de Viterbo & 23.862 & 288,58 & 82,69 & Ribeirão Preto & 95,33 & $17.704,56$ \\
\hline 32 & São Manuel & 38.342 & 650,77 & 58,92 & Sorocaba & 97,58 & $19.759,30$ \\
\hline 33 & Sarutaiá & 3.622 & 141,61 & 25,58 & Sorocaba & 81,65 & $7.622,83$ \\
\hline 34 & Sorocaba & 586.625 & 448,99 & $1.306,55$ & Sorocaba & 98,98 & $24.272,26$ \\
\hline 35 & Taquarituba & 22.291 & 448,43 & 49,71 & Sorocaba & 87,83 & $10.986,04$ \\
\hline 36 & Teodoro Sampaio & 21.386 & 1556,00 & 13,74 & Presidente Prudente & 81,20 & $10.514,25$ \\
\hline 37 & Viradouro & 17.297 & 217,73 & 79,44 & Barretos & 97,07 & $8.306,20$ \\
\hline
\end{tabular}

DD. Densidade Demográfica; GU. Grau de Urbanização. Fonte: * IBGE, 2013; **SEADE, 2013 
O município de Aspásia (RA - São José do Rio Preto) possui a menor população (1.809 habitantes).

O município de Fernandópolis é o que possui a maior população desta região, com 69.696 habitantes (Figura 1).

Figura 1. Região Administrativa de São José do Rio Preto e localização dos municípios certificados pelo PMVA, no período 2008-2012.

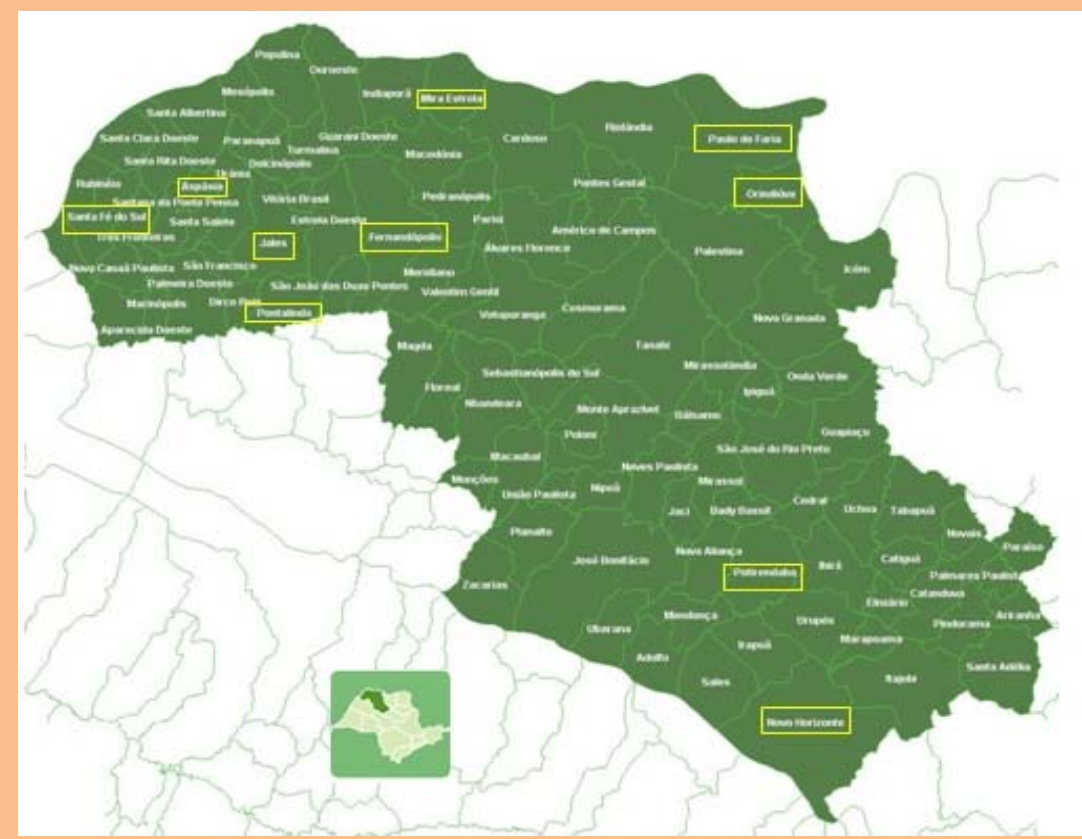

Fonte: adaptado de PLANEJAMENTO, 2013

No total dos municípios o mais populoso é o de Sorocaba (RA - Sorocaba), com 586.625 habitantes, que por sua vez também apresenta a maior densidade demográfica (1.306,55 hab/km²).

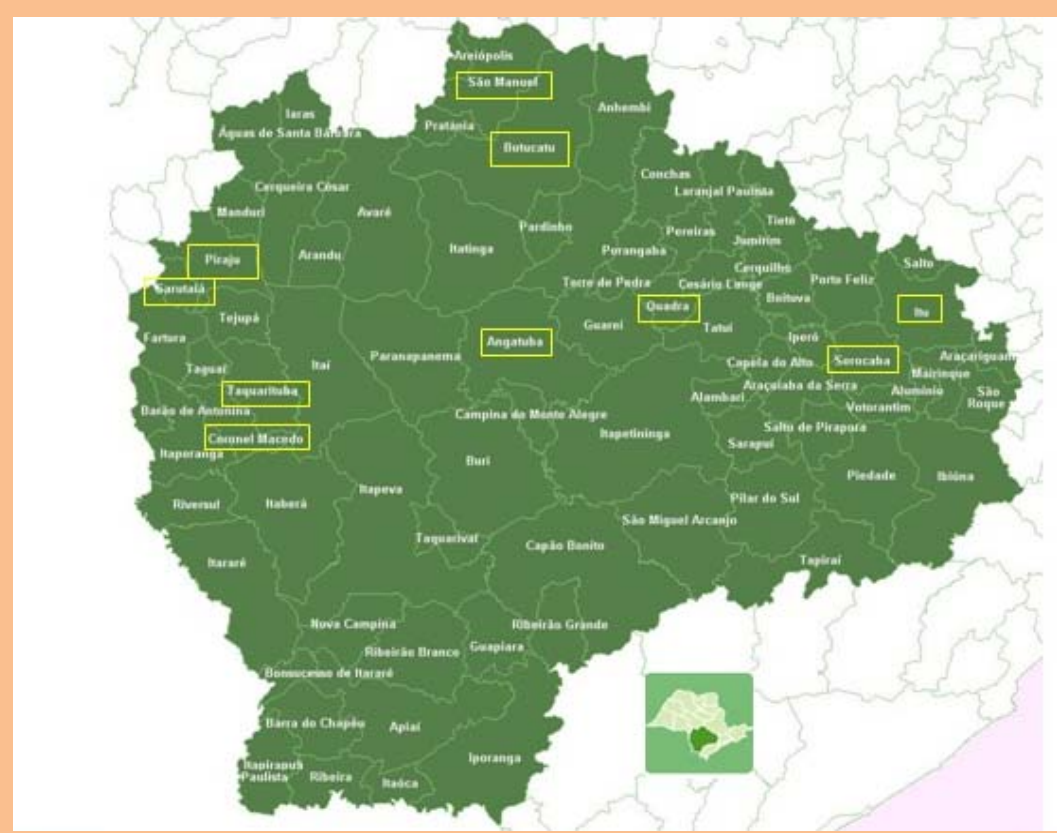

Fonte: adaptado de PLANEJAMENTO, 2013
O município de Quadra (RA - Sorocaba) possui a menor população entre os 37 identificados, com 3.236 habitantes (Figura 2).

\section{Figura 2. Região Administrativa de Sorocaba e localização dos municípioscertificados pelo PMVA, no período 2008 -2012}

\section{RDEAZUL E A ARBORIZAÇÃO URBANA}


A densidade demográfica é dada pela razão entre a população e a área do município. Pelos dados da Tabela 1, observa-se que o município Paulo de Faria (RA de São José do Rio Preto) possui a menor densidade demográfica em relação aos demais, ou seja, 11,63 habitantes por quilômetros quadrados. Observando-se as informações referentes ao grau de urbanização, o município de Sorocaba possui 98,98 \% de sua população vivendo na zona urbana. Segundo IBGE (2013) o grau de urbanização refere-se ao percentual da população urbana em relação ao total (população absoluta) do município e tem sido adotada como indicador na quantificação da arborização urbana expressa em termos de superfície de área verde/habitante, O IAV (Índice de Área Verde) ou PAV - Percentual de Áreas Verdes (OLIVEIRA, 2006).

O aumento do grau de urbanização dos municípios do Estado de São Paulo segue a mesma tendência dos municípios brasileiros (Brito, 2006), sendo que, a falta de planejamento e o crescimento desordenado da urbe têm trazido conseqüências negativas na qualidade de vida das pessoas.

Os altos níveis de urbanização evidenciados em quase todos nos municípios da Tabela 1 (com exceção de Quadra, com 25,60 \%) indicam que medidas devem ser tomadas, no sentido de proporcionar a melhoria, não só do aspecto físico urbano alterado pelos conjuntosarquitetônicos, mas também proporcionar conforto ambiental, que certamente pode ser favorecido pelo conjunto de árvores e espaços verdes criados e mantidos pelo setor público local, responsável por tal segmentodentro do município.

No Brasil é evidente que as cidades estão assumindo um papel cada vez mais significativo e carecem de estruturas e melhor delineamento das formas urbanas. É preciso repensar as cidades sob diversas óticas, incluindo-se a ambiental e substituir a urbanização tradicional (Melo; Romanini, 2007).
Desta forma Crestana et al. (2007) consideram que a implantação de um sistema de verde urbano, baseado no estabelecimento de árvores bem distribuídas no tecido urbano, está calcada nos benefícios das árvores para esse ecossistema e nas necessidades humanas para obter melhor qualidade de vida. Cidades como Sorocaba possuem quase a totalidade de seus munícipes vivendo na zona urbana e contribuindo para a elevada densidade demográfica, com isto passa a ser essencial a existência de uma arborização urbana planejada no sentido de colaborar com o bem estar dos transeuntes além de influenciar positivamente o aspecto visual urbano alterado pelo excesso de edificações.

Com vistas ao atendimento as necessidades de alteração da gestão pública administrativa municipal, o modelo de política pública ambiental, que favorece e dá suporte aos municípios, criado pela SMA do estado de São Paulo, estabelece na diretiva Arborização Urbana, critérios e pontuações que norteiam as decisões em relação à postura adotada pela administração local e a arborização urbana. As informações sobre os modelos dos critérios estabelecidos na diretiva Arborização Urbana (AU) encontram-se descritos na Tabela 2.Observa-se que em 2008 e 2009 os municípios consideraram as áreas verdes para a definição em metros quadrados por habitante. Já nos anos de 2010, 2011 e 2012 as resoluções referem-se ao levantamento do perímetro urbano. Considera-se que houve alterações tanto dos itens, quanto das notas, em todos os anos de avaliação, em relação ao Indicador de Atendimento (ID). Os itens que compõem o ID são dados por critérios e identificados com as siglas $\mathrm{AU}$, apenas nas diretivas de 2010, 2011 e 2012. Não houve alteração da nota do Indicador de ação Pró-Ativa, mas nos anos de 2010, 2011 e 2012 a descrição passa a informar que o viveiro (seja do próprio

Eliana Cristina Generoso Konrad et al 
município ou consorciado) deve fornecer mudas para a recuperação de mata ciliar.

arbóreas tanto para a arborização urbana quanto

Tabela 2. Critérios estabelecidos na da diretiva Arborização Urbana do PMVA, no período 2008-2012, em relação ao Indicador de Atendimento (IA) e em relação à Pró-Atividade do município (PRO)

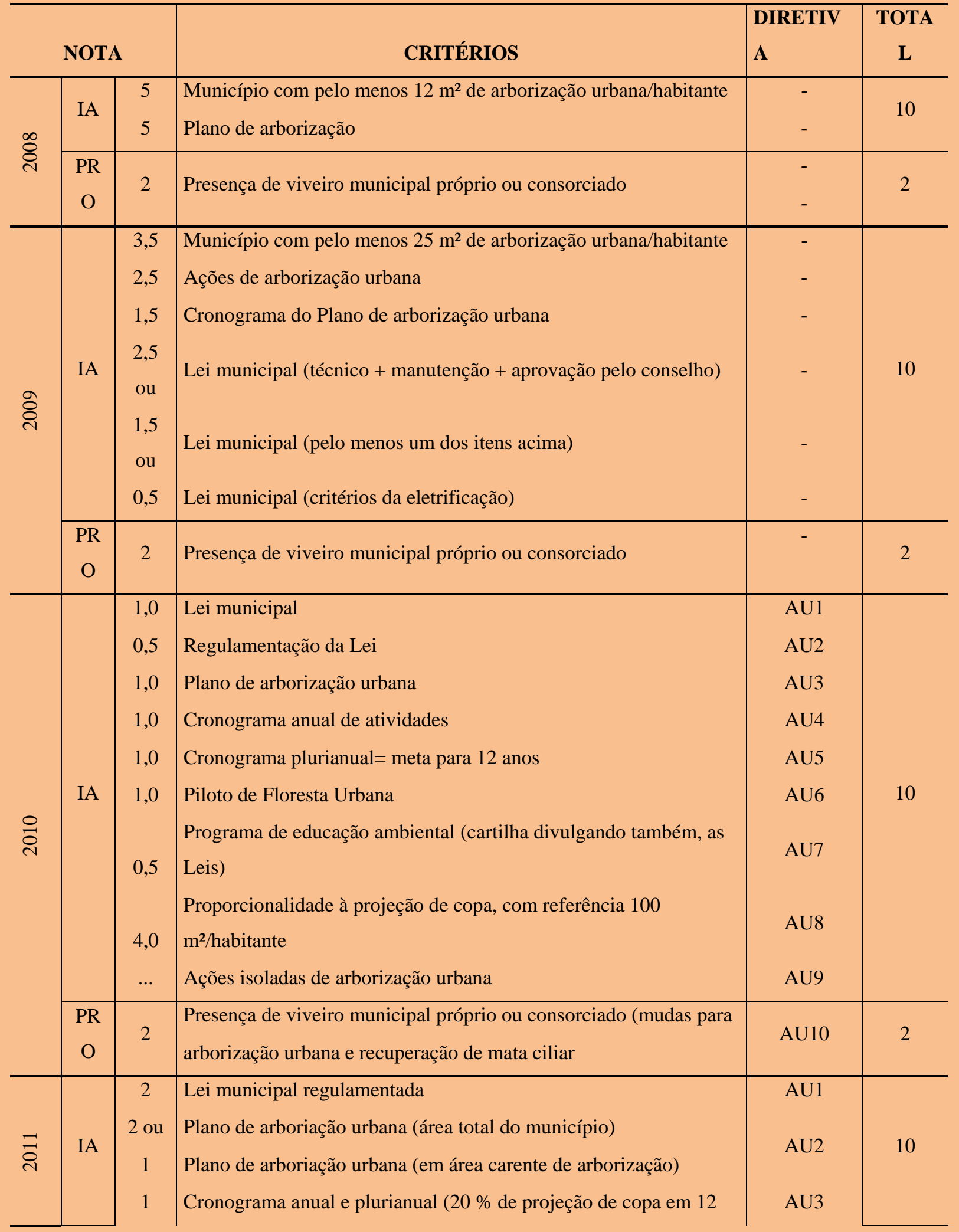




\begin{tabular}{|c|c|c|c|c|c|}
\hline & & 2 & $\begin{array}{l}\text { anos) } \\
\text { Piloto de Floresta Urbana } \\
\text { Proporcionalidade à projeção de copa, com referência a meta } \\
\text { bianual de } 8 \%\end{array}$ & AU4 & \\
\hline & $\begin{array}{c}\mathrm{PR} \\
\mathrm{O}\end{array}$ & 2 & $\begin{array}{l}\text { Presença de viveiro municipal próprio ou consorciado (mudas para } \\
\text { arborização urbana e recuperação de mata ciliar }\end{array}$ & AU6 & 2 \\
\hline 규 & IA & 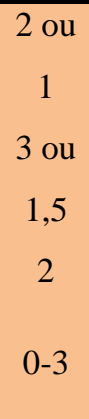 & $\begin{array}{l}\text { Lei municipal regulamentada completa } \\
\text { Lei municipal regulamentada e metade aplicada } \\
\text { Plano de arborização urbana (área total do município) } \\
\text { Plano de arborização urbana (em área carente de arborização) } \\
\text { Piloto de Floresta Urbana } \\
\text { Proporcionalidade à projeção de copa, com referência a meta } \\
\text { bianual de 8\% }\end{array}$ & $\begin{array}{l}\text { AU2 } \\
\text { AU3 } \\
\text { AU4 }\end{array}$ & 10 \\
\hline & $\begin{array}{c}\mathrm{PR} \\
\mathrm{O}\end{array}$ & 2 & $\begin{array}{l}\text { Presença de viveiro municipal próprio ou consorciado (mudas para } \\
\text { arborização urbana e recuperação de mata ciliar) }\end{array}$ & AU5 & 2 \\
\hline
\end{tabular}

Fonte:AMBIENTE, 2013

É possível observar incremento das exigências em relação aos critérios ao longo do período 20082012, sendo que, o ID passa a distribuir melhor as notas em relação aos critérios, a serem atendidos pelo município. Na estrutura das diretivas de 2011 e 2012 observa-se a melhor distribuição dos critérios, o que facilita o atendimento, pelos municípios, aos itens que estão sendo sugeridos.

Observa-se que o Indicador de Atendimento, que trata da arborização urbana por habitante, $12 \mathrm{~m}^{2}$ no ano de 2008, passa a $25 \mathrm{~m}^{2} /$ habitante, no ano de 2009. No ano de 2010 os critérios são dados por projeção de copa, referente a $100 \mathrm{~m}^{2} /$ habitante. Em 2011 a proporcionalidade estabelecida não é clara, o que dificulta o entendimento do critério. Desta forma identifica-se falta de padronização dos termos que retratam a quantidade de árvores no município. Considera-se que estas mudanças foram realizadas para melhor atendimento às exigências, pelos municípios e também por ser um tema que ainda está sendo discutido dentro das questões ambientais e necessita de uma padronização de conceitos

Em relação ao número de indivíduos arbóreos, apesar da diretiva AU em 2011 e 2012 sugerir uma referência de 100 m²/hab de projeção de copa, não a faz, com base científica para definição deste valor. Segundo Cavalheiro; Del Picchia (1992) o índice de área verde é denominado pela quantidade de espaços livres de uso público por habitante da cidade. Algumas recomendações, como $12 \mathrm{~m}^{2} \mathrm{de}$ área verde por habitante tem sido bastante difundida, mas nem mesmo a ONU (Organização das Nações Unidas) e a OMS (Organização Mundial de Saúde fazem referencias a este valor (CAVALHEIRO; DEL PICCHIA, 1992).

Os critérios de avaliação do Indicador de Atendimento (ID) e do Indicador das ações Próativas (PRO) da diretiva AU, nos anos de 2008, 2009, 2010, 2011 e 2012 encontram-se descritos na Resolução SMA No 09, Resolução SMA N N $^{\circ}$ 5, Resolução SMA No 17, Resolução SMA No 36 e 
Resolução SMA N $\mathrm{N}^{\mathrm{O}}$ 19, respectivamente (AMBIENTE, 2013).

Nos dados descritos na Tabela 3 observa-se que o município de Santa fé do Sulocupa a primeira colocação no ranking nos anos de 2008, 2009 e
2011, sendo o município que mais obteve certificações. Na seqüência está o município de Santa Rosa de Viterbo, certificado nos anos de 2008, 2009 e 2012.

Tabela 3.Ranking, pontuação geral e pontuação da diretiva Arborização Urbana,dos 10 primeiros municípios do PMVA,no período 2008- 2012

\begin{tabular}{|c|c|c|c|}
\hline & $\begin{array}{l}\text { RANKING DOS } \\
\text { MUNICÍPIOS }\end{array}$ & $\begin{array}{c}\text { PONTUAÇÃO } \\
\text { GERAL* }\end{array}$ & $\begin{array}{c}\text { PONTUAÇÃO } \\
\text { DIRETIVA ARBORIZAÇÃO } \\
\text { URBANA }\end{array}$ \\
\hline \multicolumn{4}{|c|}{2008} \\
\hline 1 & Santa Fé do Sul & 94,96 & - \\
\hline 2 & Angatuba & 94,06 & - \\
\hline 3 & Gabriel Monteiro & 92,84 & - \\
\hline 4 & Santa Rosa de Viterbo & 90,64 & - \\
\hline 5 & Piraju & 90,48 & - \\
\hline 6 & Novo Horizonte & 89,80 & - \\
\hline 7 & Luis Antônio & 89,64 & - \\
\hline 8 & São Manuel & 89,27 & - \\
\hline 9 & Barretos & 89,04 & - \\
\hline 10 & Piacatu & 88,78 & - \\
\hline \multicolumn{4}{|c|}{2009} \\
\hline 1 & Santa Fé do Sul & 94,40 & - \\
\hline 2 & Novo Horizonte & 94,33 & - \\
\hline 3 & Guaraçaí & 94,20 & - \\
\hline 4 & Aspásia & 94,00 & - \\
\hline 5 & Taquarituba & 93,96 & - \\
\hline 6 & Teodoro Sampaio & 93,94 & - \\
\hline 7 & Buritama & 93,69 & - \\
\hline 8 & Gabriel Monteiro & 93,66 & - \\
\hline 9 & Cabrália Paulista & 93,65 & - \\
\hline 10 & Jales & 93,49 & - \\
\hline \multicolumn{4}{|c|}{2010} \\
\hline 1 & Santa Rosa de Viterbo & 94,31 & 9 \\
\hline 2 & Sarutaiá & 94,23 & 7 \\
\hline 3 & Paulo de Faria & 93,54 & - \\
\hline 4 & Martinópolis & 93,16 & 7 \\
\hline 5 & Anhumas & 92,94 & 9 \\
\hline
\end{tabular}




\begin{tabular}{ll|c|c}
6 & Altinópolis & 92,59 & 6 \\
7 & Sorocaba & 92,47 & 9 \\
8 & Lins & 92,29 & 8 \\
9 & Pontalinda & 92,09 & 8 \\
10 & Coronel Macedo & 92,08 & 7 \\
\hline \multicolumn{2}{|c}{$\mathbf{2 0 1 1}$} \\
\hline 1 & Santa Fé do Sul & 96,98 & 9 \\
2 & Viradouro & 95,84 & 9 \\
3 & Sorocaba & 95,62 & 9 \\
4 & Fernandópolis & 95,54 & 9 \\
5 & Guararapes & 95,54 & 9 \\
6 & Anhumas & 95,20 & 9 \\
7 & Orindiúva & 94,48 & 8 \\
8 & Quadra & 94,36 & 9 \\
9 & Pereira Barreto & 94,15 & 8 \\
10 & Mira Estrela & 93,90 & 9 \\
\hline \multicolumn{2}{|c}{$\mathbf{2 0 1 2}$} & 9 \\
\hline 1 & Botucatu & 9,5 \\
2 & Sorocaba & 97,27 & 9 \\
3 & Santa Rosa de Viterbo & 97,21 & 9 \\
4 & Araraquara & 95,90 & 9 \\
5 & Fernandópolis & 95,51 & 9 \\
6 & Piacatu & 95,12 & 9 \\
7 & Potirendaba & 94,44 & 9 \\
8 & Itu & 94,37 & 9 \\
9 & Santa Fé do Sul & 94,01 & 9 \\
10 & Taquarituba & 9 \\
\hline & \multicolumn{2}{|c}{} & 9 \\
\hline
\end{tabular}

Fonte: AMBIENTE, 2013

Os dados detalhados sobre a pontuação dos critérios na Diretiva Arborização urbana estão disponibilizados apenas para os anos de 2011 e 2012 (no site da SMA). Observa-se que nenhum município atingiu o valor máximo da diretiva (10 pontos), sendo que a pontuação da tabela já está considerando os dois pontos de Pró-atividade. É importante considerar que, cada diretiva possui um peso na equação final, que determina a pontuação para estabelecer o ranking, em todos os anos do PMVA, a diretiva AU teve peso 0,5, segundo as
Resoluções estabelecidas para os respectivos anos de avaliação (AMBIENTE, 2013).

A pontuação relaciona-se diretamente ao cumprimento da diretiva, que por sua vez está relacionada com ações desenvolvidas no município. Desta forma pode-se constatar que, se em um ano o município já desenvolveu uma ação e foi pontuado, para que esta pontuação aumente ou para que novos critérios possam ser atendidos, novos projetos, programas, leis e outras articulações do poder administrativo devem ser criados. Neste contexto Eliana Cristina Generoso Konrad et al 
não há respaldo direto da SMA e considerando-se as limitações administrativas locais estes fatores são e serão atendidos envolvendo-se ações inovadoras, capacitações, investimentos financeiros e adequação da estrutura física e dos atores responsáveis diretamente pela gestão da arborização urbana do município.

Na Tabela 4 encontram-se os dados da quantificação de árvores nos municípios, ou seja, a área de projeção de copa considerando-se a área em metros quadrados e o número de habitantes (informação não divulgada para os anos 2008 e 2009 pela SMA.

Para o entendimento destes dados é pertinente considerar as informações sobre os indicadores de atendimento constantes da Tabela 2.Observando-se as informações (Tabela 2) é possível identificar a quantidade mínima, que deve ser considerada no plantio de novos indivíduos. Nos anos de 2011 e 2012 a quantidade de árvores é solicitada em porcentagem e não em projeção de copa, como nos anos anteriores (12m²/hab em 2008 e 25 m²/hab em 2009). A indicação (2011 e2012) considera a obtenção de 20 \% de copa em área urbana em 12 anos e $8 \%$ anual. Portanto não foi possível comparar as informações da Tabela 4, sobre a projeção de copa, ou seja, se houve evolução nos plantios nos sucessivos anos do PMVA, pois os dados divulgados não condizem com o formato estabelecido na diretiva, através dos indicadores nos anos de 2010, 2011 e 2012.

Tabela 4. Projeção de copa dos 10 primeiros municípios certificados noPMVA, no período 2010-2012

\begin{tabular}{|c|c|c|}
\hline \multicolumn{2}{|r|}{ MUNICÍPIO } & $\begin{array}{c}\text { PROJEÇÃO DE } \\
\text { COPA(m²/hab) }\end{array}$ \\
\hline \multicolumn{3}{|c|}{2010} \\
\hline 1 & Santa Rosa de Viterbo & 13,70 \\
\hline 2 & Sarutaiá & 56,60 \\
\hline 3 & Paulo de Faria & - \\
\hline 4 & Martinópolis & 6,80 \\
\hline 5 & Anhumas & 4,00 \\
\hline 6 & Altinópolis & 42,00 \\
\hline 7 & Sorocaba & 9,57 \\
\hline 8 & Lins & 5,51 \\
\hline 9 & Pontalinda & 25,84 \\
\hline 10 & Coronel Macedo & 11,00 \\
\hline \multicolumn{3}{|c|}{2011} \\
\hline 1 & Santa Fé do Sul & 10,11 \\
\hline 2 & Viradouro & 8,10 \\
\hline 3 & Sorocaba & 9,57 \\
\hline 4 & Fernandópolis & 12,85 \\
\hline 5 & Guararapes & 5,36 \\
\hline 6 & Anhumas & 4,00 \\
\hline 7 & Orindiúva & 31,17 \\
\hline
\end{tabular}

O PROGRAMA MUNICÍPIO VERDEAZUL E A ARBORIZAÇÃO URBANA 


\begin{tabular}{ll|l}
8 & Quadra & 7,71 \\
9 & Pereira Barreto & 9,80 \\
10 & Mira Estrela & 2,35 \\
\hline \multicolumn{2}{|c}{$\mathbf{2 0 1 2}$} \\
\hline 1 & Botucatu & 17,00 \\
2 & Sorocaba & 16,35 \\
3 & Santa Rosa de Viterbo & 14,05 \\
4 & Araraquara & 26,19 \\
5 & Fernandópolis & 12,80 \\
6 & Piacatu & 14,14 \\
7 & Potirendaba & 4,20 \\
8 & Itu & 15,00 \\
9 & Santa Fé do Sul & 10,11 \\
10 & Taquarituba & 19,70 \\
\hline
\end{tabular}

Apesar da diversidade de conceitos encontrados na literatura sobre espaços verdes urbanos, as áreas verdes são tidas como espaços com predomínio de vegetação arbórea (Cavaleiro e Del Picchia, 1992; Lima et al., 1994; Loboda e De Angelis, 2005; Harder et al., 2006; Melo e Romanini, 2007), já a arborização urbana constitui elementos vegetais de porte arbóreo, no perímetro urbano, não integrando as áreas verdes (Cavaleiro e Del Picchia, 1992; Lima et al., 1994). Dentro deste contexto existe a possibilidade de considerar que a definição de projeção de copa encontrada nas resoluções da SMA também foi influenciada pela dificuldade de entendimento dos termos que envolvem os assuntos relacionados à arborização urbana e suas formas de quantificação.

Implantar árvores no espaço urbano requer planejamentoe nem sempre é possível idealizar a arborização de acordo com a real necessidade do município. Assim como em outras áreas que envolva questões ambientais, o ser humano necessita renovar seus conceitos, tradições e métodos de gestão, acessando novas tecnologias, para que, com pequenas ações possa interferir positivamente nas composições do ambiente urbano.

\section{CONCLUSÕES}

De acordo com os resultados obtidos conclui-se que os municípios que participaram das cinco edições do Município VerdeAzul, encontram-se distribuídos em oito das quinze regiões administrativas do estado de São Paulo. Houve evolução quanto às exigências dos critérios dispostos na diretiva Arborização Urbana no período analisado. O município de Santa Fé do Sul foi certificado nos anos de 2008, 2009, 2011 e 2012. 
AMBIENTE. Secretaria do Meio Ambiente. São Paulo. 21 Projetos Ambientais Estratégicos. Disponível em http://www.ambiente.sp.gov.br/projetos.php. Acesso em: 23 de Jan, 2013.

ASSOCIAÇÃO BRASILEIRA DE NORMAS TÉCNICAS - ABNT. Rótulo ecológico. Disponível em: <rotulo.abnt.org.br>. Acesso em: 05 set. 2013.

BARBEDO, A. S. C.; BIANCHI, C. G.; KELLER, L. R.; ORTEGA, M. G.; ORTEGA, S. E. H. Manual técnico de arborização urbana da cidade de São Paulo. 2 ed. São Paulo: Prefeitura Municipal/SVMA, 2005. 48p.

BRITO, F.; HORTA, C. J. G.; AMARAL, E. F. L. A urbanização recente no Brasil e as aglomerações metropolitanas. Disponível em:

<http://www.nre.seed.pr.gov.br/cascavel/arquivos/File/A_urbanizacao_no_brasil.pdf>.Acesso em: 10 mar, 2013.

CAVALHEIRO, F.; DEL PICCHIA, P. C. D. Áreas verdes:conceitos, objetivos e diretrizes para o planejamento. In: Congresso Brasileiro sobre Arborização Urbana, 1, 1992, Vitória, Anais..., Vitória: Sociedade Brasileira de Arborização Urbana, 1992. p.

CRESTANA, M. S. M.; SILVA FILHO, D. F.; BERTONI, J. E. A.; GUARDIA, J. F. C; ARAÚJO, R. T. Planejamento da floresta urbana. In_. Árvores \& Cia. Campinas, Cati, 2007. p. 1-27.

DEMATTÊ, M. E. S. P. Arborização urbana e rural. Contagro: Campinas, 2001. 34p.

HARDER, I. C. F.; RIBEIRO, R. C. S. Índices de área verde e cobertura vegetal para as praças do município de Vinhedo, SP. Revista Árvore, Viçosa, v. 30, n. 2, p. 278-282, 2006.

INSTITUTO BRASILEIRO DE GEOGRAFIA E ESTATÍSTICA. Cidades @. Disponível em:http://www.ibge.gov.br/cidadesat/topwindow>. Acesso em: 20 de Jan, 2013.

LIMA, M. L. P. CAVALHEIRO, F.; NUCCI, J. C.; SOUSA, M. A. L. B.; FIALHO, N. O.; DEL PICCHIA, P. C. D.Problemas de utilização na conceituação de termos como espaços livres, áreas verdes e correlatos. In: Congresso Brasileiro de Arborização Urbana, 2, 1994, São Luís. Anais... São Luis: Sociedade Brasileira de Arborização Urbana, 1994. p. 539-553.

LOBODA, C. R.; De ANGELIS, B. L. D. Áreas verdes públicas urbanas: conceitos, usos e funções. Ambiência, Guarapuava, v.1, n. 1, p. 125-139, 2005.

MELO, E. F. R.Q.; ROMANINI, A. A gestão da arborização urbana na cidade de Passo Fundo. Revista Brasileira de Arborização Urbana, São Paulo, v. 2, n. 1, p. 1-16, 2007.

OLIVEIRA, C. H.; SANTOS, J. E.; PIRES, J. S. Indicadores de arborização urbana da cidade de São Carlos (SP) com o uso do SIG-IDRISI. Disponível em: http://ecologia.ib.usp.br/sebecologia/revista/n199/INDICADORES.html. Acesso em: fev. 2013.

PLANEJAMENTO. Secretaria de Planejamento e Desenvolvimento Regional. Escritórios regionais: informações regionais. Disponível em: <www.planejamento.sp.gov.br/index.php?id=50>. Acesso em: 12 set. 2013.

PLANEJAMENTO. Secretaria de Economia e Planejamento. Caracterização regional do Estado de São Paulo a partir dos dados da RAIS, 2010. 418p. 
PAIVA, P. D. O. Plantas ornamentais utilizadas em paisagismo. In. Plantas ornamentais: classificação e usos em paisagismo. Lavras: UFLA/FAEPE, 2001. p. 38.

SEADE - FundaçãoSistema Estadual de Análise de Dados. Secretaria de Planejamento e Desenvolvimento Regional. Regiões administrativas do Estado de São Paulo. Disponível em: <http://www.seade.gov.br/>. Acesso em: 8 fev, 2013. 